\title{
Infusion Site Extravasation, CTCAE
}

National Cancer Institute

\section{Source}

National Cancer Institute. Infusion Site Extravasation, CT CAE. NCI Thesaurus. Code C143584.

A disorder characterized by leakage of the infusion into the surrounding tissue. Signs and symptoms may include induration, erythema, swelling, burning sensation and marked discomfort at the infusion site. 